Article

\title{
Isothermal Drying Process and its Effect on Compressive Strength of Concrete in Multiscale
}

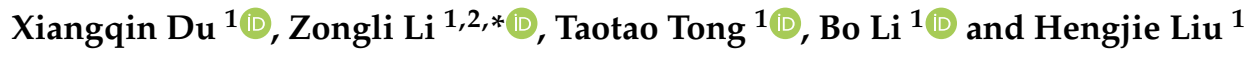 \\ 1 College of Water Resources and Architectural Engineering, Northwest A \& F University, \\ Yangling 712100, Shaanxi, China; xiangqin016@163.com (X.D.); tongtt3@163.com (T.T.); \\ nwsuaf2013@163.com (B.L.); liuhengjie002@163.com (H.L.) \\ 2 Key Laboratory of Agricultural Soil and Water Engineering in Arid and Semiarid Areas of Ministry of \\ Education, Northwest A \& F University, Yangling 712100, Shaanxi, China \\ * Correspondence: bene@nwsuaf.edu.cn; Tel.: +86-1375-989-2508
}

Received: 15 August 2019; Accepted: 23 September 2019; Published: 25 September 2019

\begin{abstract}
Drying could change the microstructure of cement-based materials and inevitably affect their mechanical properties. The isothermal drying process of concrete at three scales and its effect on compressive behavior and microstructure were investigated. The deformations of cement paste, mortar, and concrete in the drying process all exhibit the characteristics of expansion first and then shrinkage. The porosity and average pore diameter increase after drying, which is mainly attributed to the increase of pores less than $100 \mathrm{~nm}$ diameter for paste and to the pores within 100 1000 nm for mortar. Drying makes paste denser, while the bonding between paste and aggregate is weakened. Microstructural studies indicate that the increase in compressive strength of concrete caused by isothermal drying is the competition result between the strengthening effect and the weakening effect, and is related to the paste content.
\end{abstract}

Keywords: concrete; isothermal drying; compressive strength; multiscale

\section{Introduction}

Concrete, a most widely used building material at present, is a typical heterogeneous and porous material. The existence and migration of pore water would affect its mechanical properties and durability [1-4]. For concrete structures exposed to water environments, or those in an environment where humidity varies considerably, the effect of moisture content is significant and should be considered in structural design. In recent decades, investigators have achieved many satisfactory results in which strength, elastic modulus, creep, and shrinkage of concrete are generally recognized as functions of moisture content [5-7]. As a basic and most important engineering indicator of concrete, compressive strength under different moisture content has been extensively studied. Isothermal drying is generally used as an effective method to control water content of concrete in the laboratory $[1,8-10]$. When the drying temperature is not too high, a positive effect on strength termed as "drying-strengthening" occurs [11]. Studies have shown that the compressive strength of dry concrete is higher than that of saturated concrete [8-10]. Han et al. [12] also found that the drying effect on compressive strength of concrete with different strength grades was influenced by temperature, which decreased first and then increased as temperature increased from $60{ }^{\circ} \mathrm{C}$ to $150{ }^{\circ} \mathrm{C}$. Moreover, the same conclusion can be drawn from the study of mortars $[9,13,14]$. What happens during the drying process of concrete that affects the strength of concrete, and is this effect the same in different scales? These questions have not yet been clarified.

As a multiphase material composed of paste, aggregates, an interface transition zone, and pores with different sizes, the macro-mechanical properties of concrete depend on its microstructure and 
properties of components. The improvement in compressive strength due to drying must be related to changes in microstructure and the interaction of individual components [15]. Wittmann [16] pointed out that the decrease of humidity caused by drying would cause the increase of surface tension of hardened cement paste, consequently resulting in drying shrinkage and strength increase. Maruyama et al. [17] explained the variation in compressive strength of concrete caused by drying as the joint interaction of the change in paste strength and damage accumulation due to different volume changes between aggregate and mortar. He further indicated that the variation in strength of cement paste caused by drying is attributed to its microstructural change as well as C-S-H (Calcium-Silicate-Hydrate) globule densification [18]. Many researchers focused mainly on the change of compressive strength caused by drying, however, few detailed descriptions about the drying process of concrete, as well as generally accepted explanations about the relationship of changes occurring in drying process and the compressive strength, have yet been reached. To understand the nature of the drying effect on compressive strength of concrete, it is necessary to experimentally study its drying process. The isothermal drying process of concrete differs at different scales due to the multiscale nature and complex microstructure. In this paper, experimental studies were carried out to investigate the drying process and the drying effect on the compressive strength at three scales—cement paste, mortar, and concrete, and some explanations for strength changes were given.

\section{Materials and Methods}

\subsection{Materials and Sample Preparation}

Ordinary Portland cement (P.O 42.5 R) produced in Jidong Cement Plant of China was used in production of cement paste, mortar, and concrete, the standard water consumption of which is $28.78 \%$. Both fine and coarse aggregates came from Weihe River. The contents of needle particles and harmful impurities in both aggregates meet the requirements of test code for hydraulic concrete SL352-2006 [19]. Tap water was used for mixing. Tables 1-3 show the main properties of cement and aggregates. Figure 1 presents the grain compositions of fine and coarse aggregates.

Table 1. Chemical compositions (by mass) and basic physical properties of cement.

\begin{tabular}{ccccc}
\hline Density/kg $\cdot \mathbf{m}^{-3}$ & $\begin{array}{c}\text { Initial Setting } \\
\text { Time/min }\end{array}$ & $\begin{array}{c}\text { Final Setting } \\
\text { Time/min }\end{array}$ & Soundness & $\begin{array}{c}\text { Compressive Strength } \\
\text { at 28 Days/MPa }\end{array}$ \\
\hline 3150 & 90 & 320 & qualified & 37.3 \\
\hline
\end{tabular}

Table 2. The properties of fine aggregate.

\begin{tabular}{cccc}
\hline Fineness Modulus & $\begin{array}{c}\text { Dense Packing } \\
\text { Density/kg.m }{ }^{-3}\end{array}$ & $\begin{array}{c}\text { Apparent } \\
\text { Density/kg.m } \mathbf{m}^{-3}\end{array}$ & Clay Content/\% \\
\hline 2.54 & 1764 & 2560 & 0.7 \\
\hline
\end{tabular}

Table 3. The properties of coarse aggregate.

\begin{tabular}{cccc}
\hline Particle Size/cm & Bulk Density/kg.m ${ }^{-3}$ & $\begin{array}{c}\text { Apparent } \\
\text { Density } / \mathbf{k g} \cdot \mathbf{m}^{-3}\end{array}$ & Clay Content/\% \\
\hline $5-20$ & 1638 & 2680 & $0.5 \%$ \\
\hline
\end{tabular}

The mix proportions are presented in Table 4 . The size of $70.7 \mathrm{~mm} \times 70.7 \mathrm{~mm} \times 70.7 \mathrm{~mm}$ cubic specimen was adopted for cement paste, mortar, and concrete in order to make the results comparable and avoid the size effects. Specimens were immediately covered with a plastic film after casting and placed at room temperature. They were removed from PVC molds after $24 \mathrm{~h}$ and then cured in the standard curing laboratory $\left(20 \pm 2{ }^{\circ} \mathrm{C}, \mathrm{RH}>95 \%\right)$ for 28 days. Twelve specimens were prepared for 
each mixture to test compressive strength. The preparation, curing, and compressive strength test of specimens were conducted according to the national industry code [19].

Table 4. Mix proportions of cement paste, mortar, and concrete.

\begin{tabular}{cccccc}
\hline Material & Water/Cement Ratio & Cement/kg & Water/kg & Fine Aggregate/kg & Coarse Aggregate/kg \\
\hline \multirow{3}{*}{ cement paste } & 0.35 & 1498 & 524 & - & - \\
& 0.38 & 1434 & 545 & - & - \\
\multirow{2}{*}{ mortar } & 0.41 & 1375 & 564 & - & - \\
& 0.35 & 690 & 242 & 1381 & - \\
\multirow{2}{*}{ concrete } & 0.38 & 676 & 257 & 1352 & - \\
& 0.41 & 663 & 272 & 1326 & 1252 \\
& 0.35 & 368 & 129 & 735 & 1239 \\
\hline
\end{tabular}
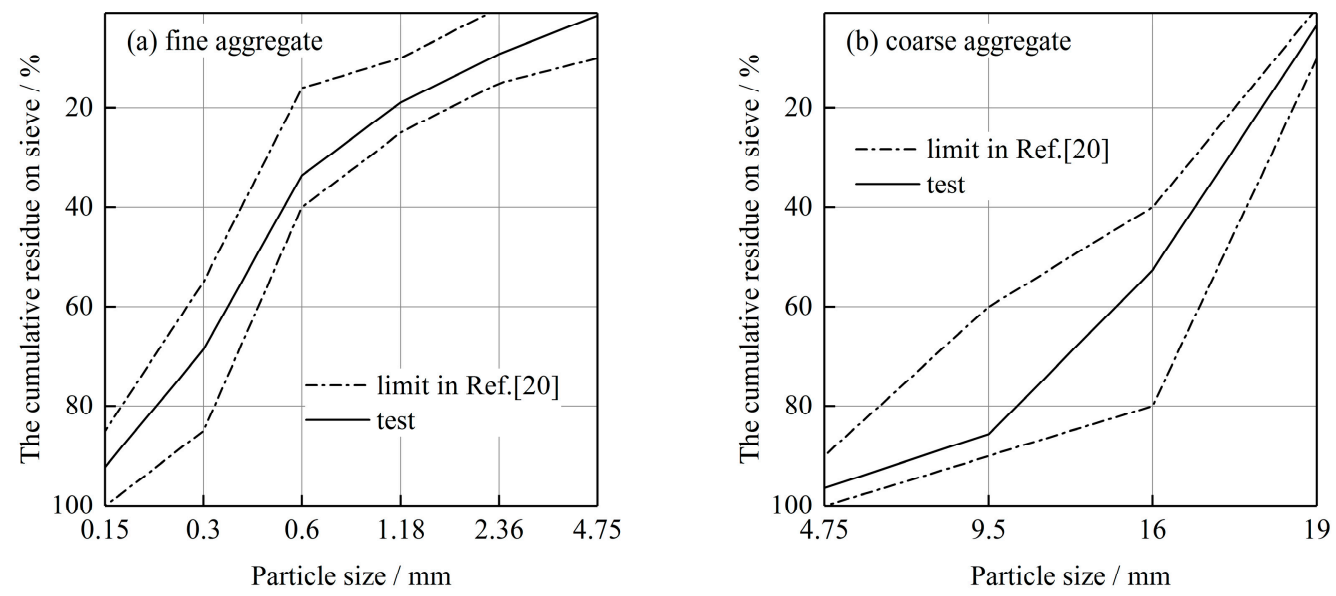

Figure 1. Grading curves of (a) fine aggregate and (b) coarse aggregate.

\subsection{Test Procedures}

\subsubsection{Isothermal Drying Process}

After being taken out of the standard curing laboratory, specimens were wiped with a wet cloth and then wrapped with two layers of plastic film for $48 \mathrm{~h}$ to ensure uniform distribution of water in specimens. Then, half of the samples of each mixture were weighed and then equally spaced in the oven, which was preheated to $105^{\circ} \mathrm{C}$, until no more mass was lost, with the water loss and deformation during the drying process being measured, while the other half was still wrapped and placed at room temperature. Oven-drying was used for specimen drying in this study because all evaporable water is removed $[20,21]$ at this temperature and this drying method is widely used by researchers $[7,9,10,12]$.

Drying operations were well-controlled to maintain the oven temperature within $105 \pm 1{ }^{\circ} \mathrm{C}$ and no heating rate was used. The air blower was always on to keep the oven dry. Specimens were weighed at regular intervals until the mass no longer changed. Each weighing was done within 5 minutes. The moisture content $\omega_{\mathrm{t}}$ and the saturation degree $S_{\mathrm{r}}$ of the specimen during drying process can be calculated according to Equations (1) and (2).

$$
\begin{aligned}
& \omega_{\mathrm{t}}=\frac{m_{\mathrm{t}}-m_{\mathrm{d}}}{m_{0}} \times 100 \% \\
& S_{\mathrm{r}}=\frac{m_{\mathrm{t}}-m_{\mathrm{d}}}{m_{0}-m_{\mathrm{d}}} \times 100 \%
\end{aligned}
$$

where $m_{0}, m_{\mathrm{t}}$, and $m_{\mathrm{d}}$ represent the mass of the specimen before drying, during drying, and after drying, respectively. 


\subsubsection{Deformation in drying process}

The length change of specimens in the drying process was measured. Four pairs of measuring points were arranged on two parallel surfaces of each cubic specimen before drying, as shown in Figure 2. A spiral micrometer was used to measure the length of the specimen in the drying process, whose measuring range and the resolution are $50 \sim 75 \mathrm{~mm}$ and $0.001 \mathrm{~mm}$, respectively. The deformation of the specimen corresponding to each measuring point was calculated as shown in Equation (3).

$$
\delta_{i}^{t}=\frac{l_{i}^{t}-l_{i}^{0}}{l_{i}^{0}} \quad(i=1,2,3,4)
$$

where $l_{i}^{0}$ and $l_{i}^{t}$ represent the initial length and the length at time $t$ in the measuring point $i$ during the drying process, respectively. Three tests were performed for each measuring points and the values were averaged. The deformation of a specimen was the average of four pairs of measuring points $\delta_{i^{\prime}}^{t}$ and the average of six specimens was regarded as the deformation corresponding to cement paste, mortar, and concrete.

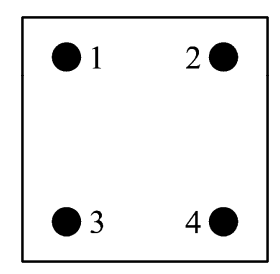

Figure 2. Measuring point layout of drying deformation.

\subsubsection{Compression test}

The WAW-1000E computer-controlled electro-hydraulic servo universal tester, with maximum testing force of $1000 \mathrm{kN}$ and the accuracy of $1 \%$, was used for the compression tests of cement paste, mortar, and concrete. When the dried specimens were cooled to room temperature, the compressive test was performed. The loading process was controlled by a personal computer, which was served as a data acquisition system and used to read data, and the stress control was adopted with the loading speed of $0.3 \mathrm{MPa} / \mathrm{s}$. The compressive strength of each specimen was calculated as shown in equation (4).

$$
\sigma_{c}=\frac{P}{A}
$$

where $\sigma_{\mathrm{c}}$ is the compressive strength of the test specimen (MPa). $P$ is the load at failure $(\mathrm{kN})$ and $A$ is the cross sectional area of specimen $\left(\mathrm{mm}^{2}\right)$ which is $70.7 \times 70.7 \mathrm{~mm}^{2}$ in this study. According to the Chinese national standard SL352-2006 [19], the compressive strength of cement paste, mortar, and concrete with different water/cement ratios was calculated by averaging strength values of six specimens.

\subsection{Microstructural Analyzing Techniques}

Thermogravimetric analyses (TGA) and differential scanning calorimetry (DSC) were carried out with the TGA/DSC 3+ (Mettler Toledo, Zurich, Switzerland) thermogravimetric thermal differential analyzer to monitor the thermal effects and investigate the kinetics of the drying process of the pastes [22]. Samples of about $25 \mathrm{mg}$ was crushed into a fine powder and heated at a constant rate of $10^{\circ} \mathrm{C} / \mathrm{min}$ from $25^{\circ} \mathrm{C}$ to $200^{\circ} \mathrm{C}$. Two blank tests were made to eliminate the errors.

Mercury intrusion porosimetry (MIP) was carried out by the AutoPore IV 9520 mercury intrusion porosimeter (Micromeritics Instrument Corpo., Atlanta, Georgia, The United States) to investigate the pore structure of concrete. Contact angle and surface tension of mercury used in this study were $130^{\circ}$ and 480 dynes/cm, respectively. The maximum mercury intrusion pressure is 4.45 psia. The range of measurable pore size was $3.2 \mathrm{~nm} \sim 360 \mu \mathrm{m}$. Three samples smaller than $10 \mathrm{~mm} \times 10 \mathrm{~mm} \times 20 \mathrm{~mm}$ were 
cut out from the middle of the saturated and dry specimens, and then dehumidified at $30^{\circ} \mathrm{C}$ before MIP test.

Scanning electron microscope (SEM) was carried out to observe the changes in morphology and microstructure. The JSM-6360LV scanning electron microscope (Japan Electronics Co., Ltd., Tokyo, Japan) was used in this study, with a low vacuum resolution of $4.0 \mathrm{~nm}, 30 \mathrm{kV}$, and a maximum magnification of $\times 300,000$. For the saturated and dry specimens, several samples smaller than $10 \mathrm{~mm}$ $\times 10 \mathrm{~mm} \times 10 \mathrm{~mm}$ were cut out from cubic specimens and carefully polished down to $1 \mu \mathrm{m}$ using diamond sprays, with petrol as a lubricant. All samples were vacuum dried and carbon sprayed before scanning.

\section{Results}

\subsection{Isothermal Drying Process}

Drying of concrete is a nonlinear moisture diffusion process [23]. When subjected to the isothermal drying condition at $105^{\circ} \mathrm{C}$, internal water continuously escapes under the temperature gradient and humidity gradient, thus the moisture content of specimens decreases gradually. With the progress of drying, the remaining moisture is being lost with increasing difficulty and much slower [24]. The water-losing rate of cement paste, mortar, and concrete during the drying process, defined as the water mass escaped from unit surface area of specimen per unit time (Unit: $\mathrm{kg} /\left(\mathrm{m}^{2} \cdot \mathrm{h}\right)$ ), was plotted in Figure 3.

It is evident from Figure 3 that the water-losing rate of cement paste reached the maximum value rapidly and then gradually decreased, while that of mortar and concrete showed a trend of rising first and then falling, which is similar to the observation of Zhang et al. [25]. This isothermal drying process can be divided into three stages: rising-rate drying stage, falling-rate drying stage, and slow drying stage. When the water-losing rate is less than $0.01 \mathrm{~kg} /\left(\mathrm{m}^{2} \cdot \mathrm{h}\right)$, it could be considered that the slow drying stage begins, and when it is less than $0.001 \mathrm{~kg} /\left(\mathrm{m}^{2} \cdot \mathrm{h}\right)$, the specimen is considered to be completely dry. In rising-rate drying stage, a moisture gradient and temperature gradient develops easily within the specimen. Internal water continuously migrates outward through interconnected microcracks and pores intrinsic in cement-based materials, resulting in the rise of the water-losing rate. The duration of this stage of cement paste, mortar, and concrete is $\leq 1 \mathrm{~h}, 2 \mathrm{~h}$, and $4 \mathrm{~h}$ respectively, shown in Figure 3a-c, and the water loss accounts for about 5.9\% 9.1\%, 12.2\% 15.1\%, and 31.7\% 35.1\% of the total water loss. In falling-rate drying stage, there are less temperature gradients inside the specimen due to continuous heating for long time. When the water diffusion inside the specimen is not sufficient to supply the water evaporation on the specimen's outside surface, drying surface would spread to the internal section of the specimen. The duration of this stage is $\sim 48 \mathrm{~h}, 40 \mathrm{~h}$, and $30 \mathrm{~h}$, and the water loss accounts for about $84.7 \% \sim 86.3 \%, 74.8 \% \sim 77.3 \%$, and $50.7 \% \sim 53.5 \%$ of the total water loss, respectively, for cement paste, mortar, and concrete. In the slow drying stage, drying takes place entirely in the internal of the specimen. Water removal becomes more and more difficult because of the very low moisture gradient and the hindrance of hydration products and aggregates. This stage lasts longest but the water loss of cement paste, mortar, and concrete only accounts for $6.5 \%$ 12.4\% of the total water loss. Table 5 suggests that the time required for completely dry state, final water loss, and maximum water-losing rate all increase with increasing the mass fraction of paste. 

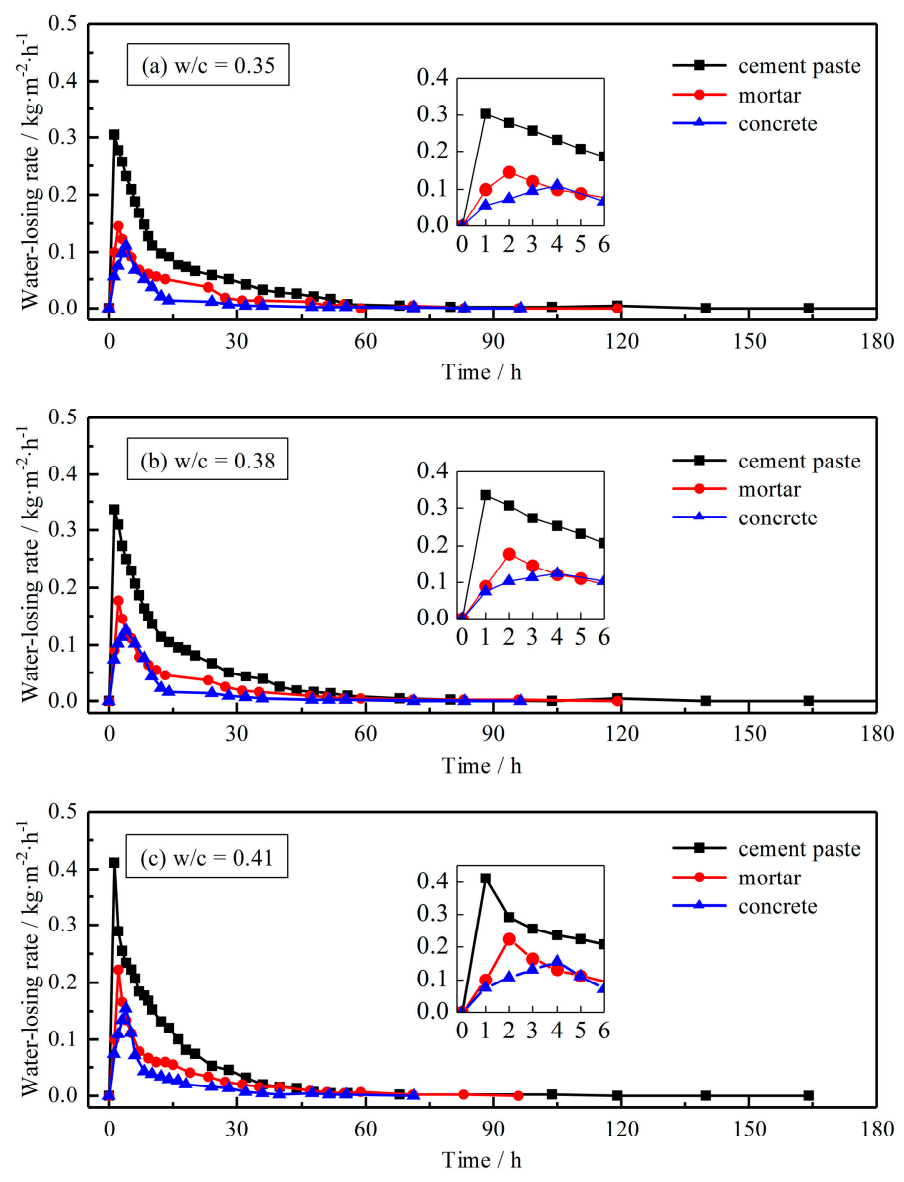

Figure 3. Water-losing rate of cement paste, mortar, and concrete.

Table 5. Drying results of cement paste, mortar, and concrete.

\begin{tabular}{|c|c|c|c|c|c|}
\hline $\begin{array}{c}\text { Water/Cement } \\
\text { Ratio }\end{array}$ & Material & $\begin{array}{c}\text { Mass Fraction } \\
\text { of Paste/\% }\end{array}$ & $\begin{array}{c}\text { Time Required } \\
\text { to Completely } \\
\text { Dry State/h }\end{array}$ & $\begin{array}{c}\text { Water Loss } \\
\text { (by Mass)/\% }\end{array}$ & $\begin{array}{c}\text { Maximum } \\
\text { Water-Losing } \\
\text { Rate } /\left(\mathrm{kg} \cdot \mathrm{m}^{-2} \cdot \mathrm{h}^{-1}\right)\end{array}$ \\
\hline \multirow{4}{*}{0.35} & cement paste & 1.0 & 180 & 16.832 & 0.304 \\
\hline & mortar & 0.403 & 120 & 6.817 & 0.144 \\
\hline & concrete & 0.200 & 80 & 2.950 & 0.111 \\
\hline & cement paste & 1.0 & 172 & 18.268 & 0.338 \\
\hline \multirow[t]{2}{*}{0.38} & mortar & 0.408 & 104 & 7.289 & 0.178 \\
\hline & concrete & 0.203 & 72 & 3.135 & 0.111 \\
\hline \multirow{3}{*}{0.41} & cement paste & 1.0 & 164 & 19.483 & 0.411 \\
\hline & mortar & 0.413 & 96 & 7.978 & 0.222 \\
\hline & concrete & 0.207 & 68 & 4.204 & 0.154 \\
\hline
\end{tabular}

\subsection{Compression Test}

\subsubsection{Compression Strength}

In this study, the drying effect on compressive strength is represented by the relative compressive strength, defined as the ratio of compressive strength in dry state to that in saturated state. As evident from Figure 4, the compressive strength of dry specimens was higher $23.91 \% \sim 25.73 \%, 13.11 \% \sim 15.45 \%$, and $4.23 \% \sim 6.18 \%$ than that of saturated specimens, respectively, for cement paste, mortar, and concrete. The strengthening effect of isothermal drying on compressive strength is significant and differs at three scales. Water/cement ratio seems to have little effect on this effect. 


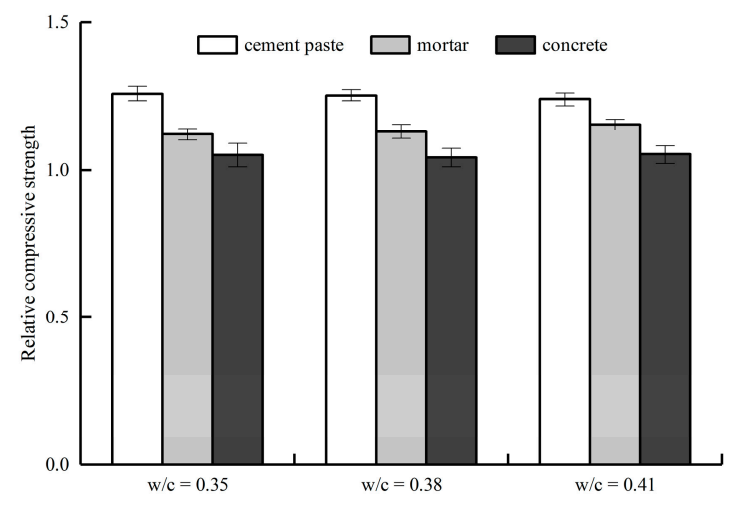

Figure 4. Relative compressive strength of cement paste, mortar, and concrete.

\subsubsection{Failure Mode}

In the observation of failure specimens of cement paste, mortar, and concrete, it was found that for the three water/cement ratios in this study the failure mode is quite different in saturated and dry states. The saturated specimen fails with a clunk sound, while the dry specimen fails with a clear blasting sound. As shown in Figure 5, the crack development and the final fracture are basically symmetrical in shape by observing the fracture shape of specimen. When the saturated specimen is damaged, its surfaces fall off seriously, presenting a typical pyramid failure mode with only a few aggregates fractured. However, the dry specimen presents a columnar failure mode with several vertical cracks on the specimen's surface along the loading direction, more aggregates are fractured, and fragments are stiffer than that of the saturated specimen. So, the drying effect on compressive failure mode of cement-based materials is obvious.

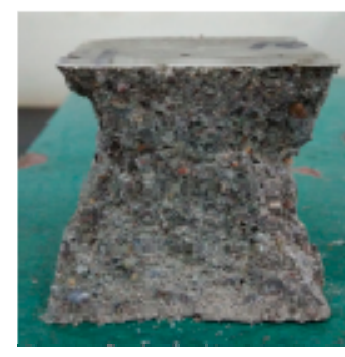

(a)

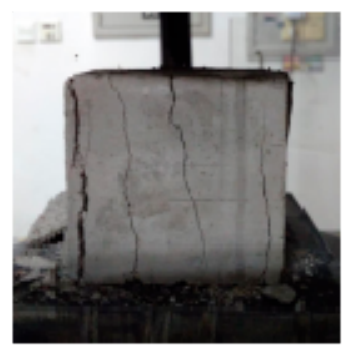

(b)

Figure 5. (a) The typical pyramid failure mode of a saturated specimen, (b) the columnar failure mode of a dry specimen.

\subsection{Drying Deformation}

Figure $6 \mathrm{a}-\mathrm{c}$ displays the deformations of cement paste, mortar, and concrete in the drying process (calculated by formula (2)). It should be noted that the deformation here refers to the average deformation in the specimen. Obviously, the deformation develops similarly at three scales, but is quite different in magnitude. The main findings were: (1) the deformation at three scales is characterized as expansion first and then shrinkage. The deformation shown in Figure 6 was the result of superimposition of expansion caused by heating and shrinkage due to water loss. (2) The deformation of cement paste is significantly larger than the deformation of mortar, which is larger than that of concrete. (3) When $S_{\mathrm{r}}$ is high, the deformation is expansion, and when $S_{\mathrm{r}}$ is low, the deformation is shrinkage. (4) The specimen recovers to its initial length when $S_{\mathrm{r}}$ is reduced to a specific value, which is about $60 \%, 50 \%$, and $15 \%$ for cement paste, mortar, and concrete, respectively. (5) The shrinkage of specimen increases significantly when $S_{r}$ is reduced below a specific value, which is about $30 \%, 25 \%$, and $10 \%$ for cement paste, mortar, and concrete, respectively. From the above 
analysis, it can be concluded that drying affects the deformation evolution of cement-based materials significantly. Moreover, Figure $6 \mathrm{a}-\mathrm{c}$ indicates that this drying effect varies at three different scales. While the expansive deformations of cement paste, mortar, and concrete are comparable in magnitude, the deformation of cement paste develops most dramatically with the decrease of $S_{\mathrm{r}}$ and gains the maximum final shrinkage, mortar is next, and concrete is minimum.

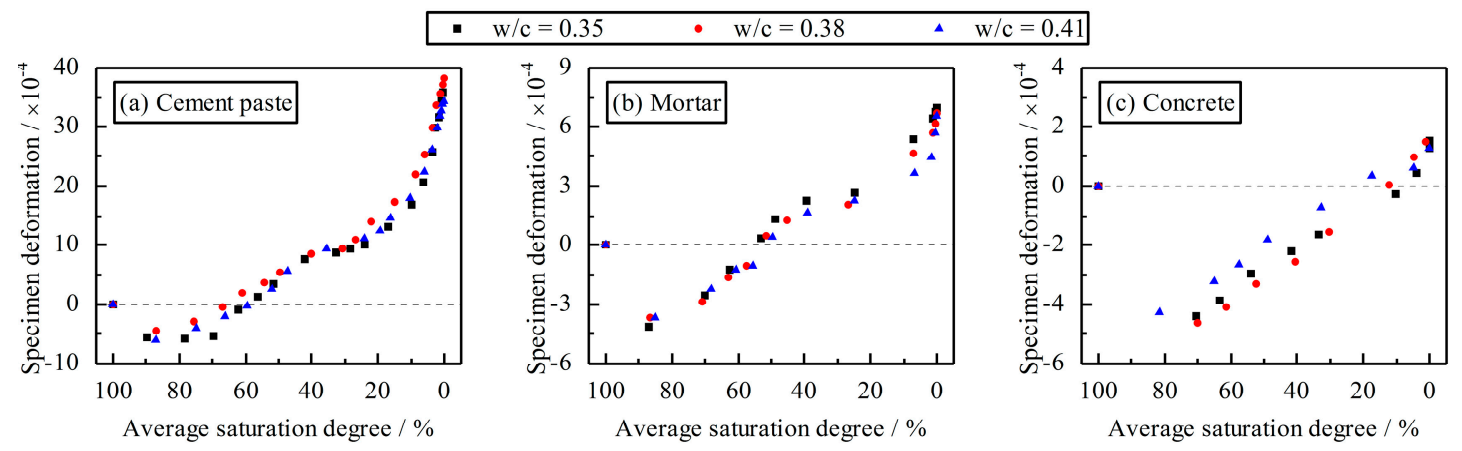

Figure 6. Deformations in drying process of concrete at three scales, (a) cement paste (b) mortar (c) concrete.

\subsection{Microstructure Analysis}

In this section, microstructure changes occurring in the isothermal drying process were investigated to provide an explanation for the differences in compressive behavior between saturated and dry concrete at three scales.

\subsubsection{TGA/DSC Analysis}

The results of relative mass change and heat flow of hardened cement paste during the heating process are shown in Figure 7a-c. TGA curves of three water/cement ratios exhibited a continuous mass loss during heating up to $200^{\circ} \mathrm{C}$, which indicates the thermal stability of hardened cement paste within the temperature range of this test, and nothing else is lost except water. Two endothermic peaks appeared in the DSC curve, one at $\sim 75^{\circ} \mathrm{C}$ and the other at $\sim 100{ }^{\circ} \mathrm{C}$. The first endothermic peak may be attributed to the dehydration of ettringite [26], and the second may be caused by the removal of adsorbed water in C-S-H [27]. That is, the dehydration of ettringite and C-S-H occurs under the drying condition used in this study $\left(105^{\circ} \mathrm{C}\right)$, which changes the composition of the hydration products. As a result, this change would influence the shrinkage, creep, and mechanical properties of cement-based materials. 

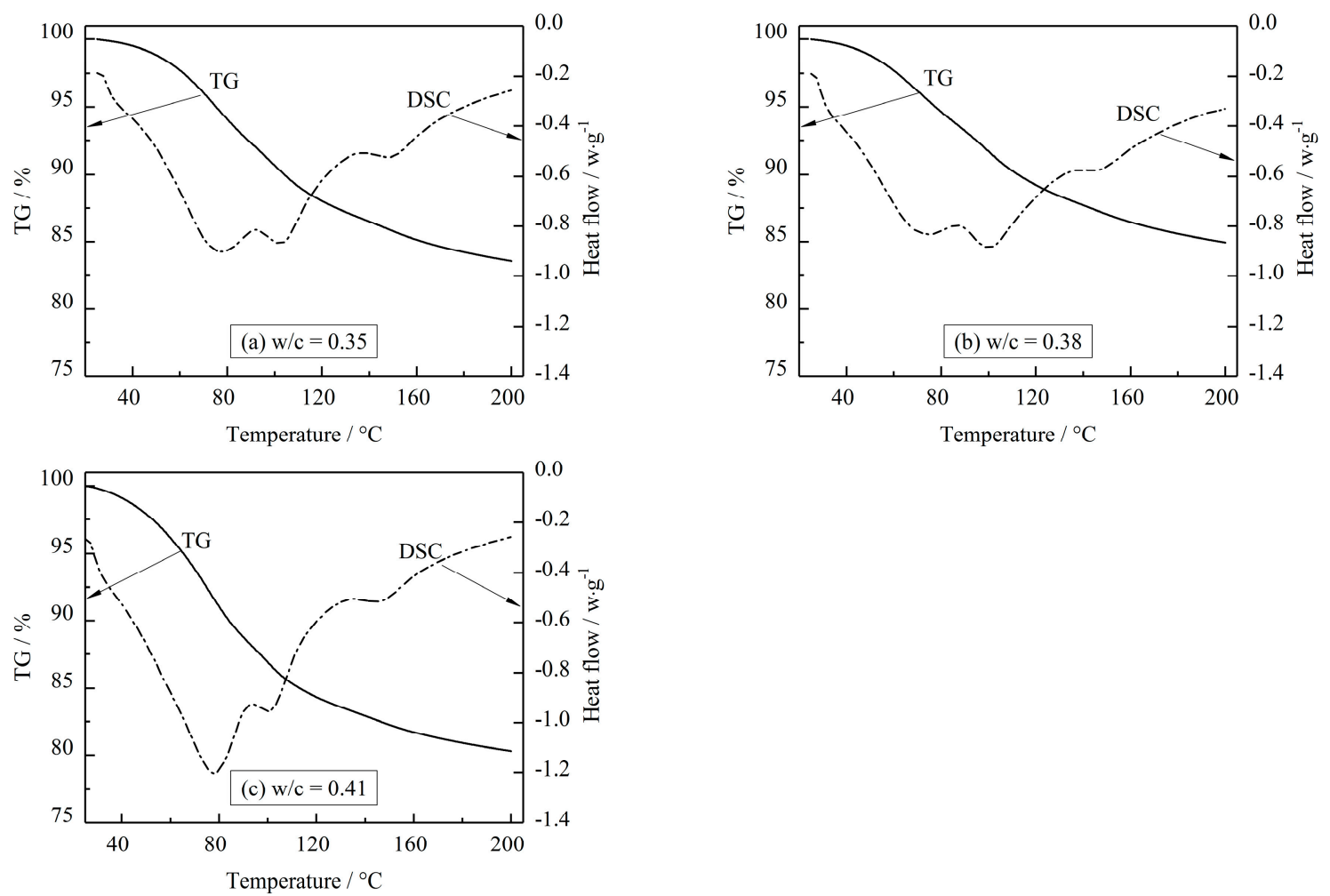

Figure 7. TGA/DSC curve of hardened cement paste.

\subsubsection{MIP Results Analysis}

Table 6 presents the MIP results and the integral curve of pore size distribution, respectively, where all data listed are the weighed average of three samples. It was found that: (1) dry samples have higher porosity and larger average pore diameter. After drying, porosity increased by $54.48 \%$ and $38.89 \%$, and the average pore diameter increased by $72.48 \%$ and $521 \%$, respectively, for cement paste and mortar; (2) the increase of porosity was mainly attributed to pores of less than $100 \mathrm{~nm}$ diameter for cement paste, and to pores within 100 1000 nm for mortar; (3) it should be mentioned that cement paste has the higher porosity and lower density than mortar just because of the introduction of aggregate [28]. Table 6 indicates that isothermal drying coarsened the pore size distribution of paste and mortar. As the increase of porosity and average pore diameter is harmful to strength, there seem to be contradictory results, with the experimental results of strength increases (Figure 4) caused by isothermal drying at three scales. Therefore, there must be other factors that contribute to the strength increase.

\subsubsection{SEM Analysis}

SEM images of specimen in saturated and dry states are shown in Figure 8. It is evident from Figure 8a that there are clusters of amorphous C-S-H gel, needle ettringite, and plate-like $\mathrm{Ca}(\mathrm{OH})_{2}$ in the paste zone both of saturated and dry specimen. The difference is that the solid matrix of dry specimen seems to become denser and finer, and there seems more needle-like hydration products. However, from Figure $8 \mathrm{~b}$ one can see that, in the saturated sample there is a thin adsorption layer around the aggregate, while in the dry sample the aggregate edge is clear and there is no adsorption layer. This indicates that the bond between aggregate and paste was weakened in drying process. 
Table 6. MIP results (water/cement ratio $=0.41$ ).

\begin{tabular}{ccccccc}
\hline \multirow{2}{*}{ Material } & \multirow{2}{*}{ State } & \multicolumn{4}{c}{ Porosity/\% } & $\begin{array}{c}\text { Average Pore } \\
\text { Diameter/nm }\end{array}$ \\
\cline { 3 - 6 } & & $\mathbf{< 1 0 0} \mathbf{~ n m}$ & $\mathbf{1 0 0 ~ 1 0 0 0 ~} \mathbf{~ n m}$ & $\mathbf{> 1 0 0 0} \mathbf{~ n m}$ & Total Porosity & \\
\hline \multirow{2}{*}{ Cement paste } & Saturated & 11.98 & 0.51 & 0.48 & 12.97 & 10.9 \\
& Dry & 18.70 & 0.45 & 0.89 & 20.04. & 18.8 \\
\multirow{2}{*}{ Mortar } & Saturated & 4.33 & 2.60 & 3.00 & 9.93 & 17.7 \\
& Dry & 3.29 & 7.64 & 2.85 & 13.78 & 110 \\
\hline
\end{tabular}

In the drying process of cement-based materials, some changes take place: (1) heating at $105{ }^{\circ} \mathrm{C}$ promotes further hydration of dehydrated cement grains and increases the amount of hydration products, resulting in a denser microstructure; (2) water loss results in the increase of surface free energy [16] and causes solid phase compaction, which was considered to be the result of the packing rearrangement of C-S-H particles [29] or the decrease of interlayer thickness within gel particles; (3) the dehydration of ettringite and C-S-H (Figure 7) leads to changes in the compositions of hydration products and the contraction in their volume; (4) the differences in thermal properties between paste and aggregate allows microcracks to generate and grow in their interface. The expansion of aggregate recovers after the specimen cools to room temperature, while the shrinkage of paste due to water loss is unrecoverable, which weakens the bonding between aggregate and paste and even results in the debonding of them. These physicochemical changes alter the microstructure of concrete and, thus, cause changes in compressive behavior. On one hand, the denser the structure of cement-based materials, the higher its strength, so the densified microstructure of paste is beneficial to concrete strength, as shown in Figure 8a. On the other hand, the weaker the bonding between paste and aggregate, the lower the strength, so the weakened bonding between aggregate and paste is harmful to concrete strength, as shown in Figure 8b. Both of the above opposite effects are associated with drying. Whether the compressive strength increases or decreases after drying depends on which of the two effects dominates.
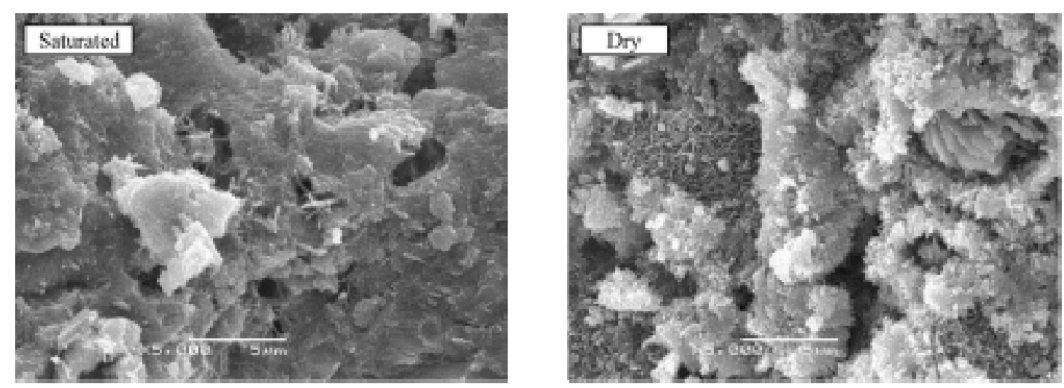

(a) Paste zone $(\times 5000)$
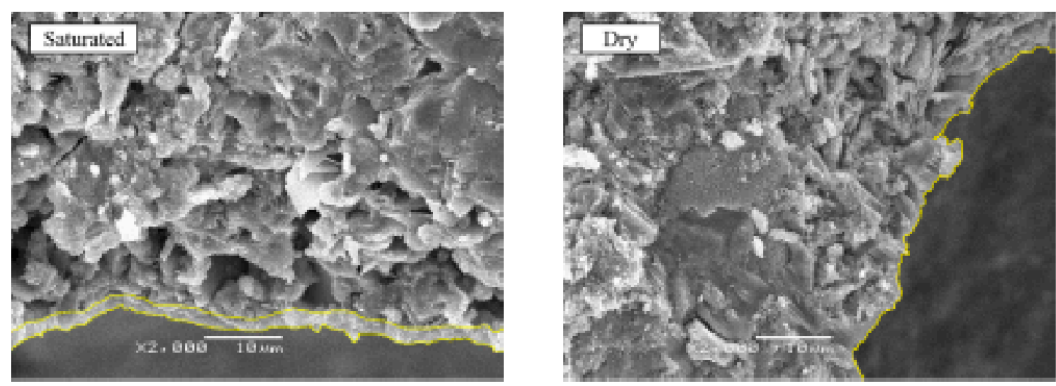

(b) Aggregate-paste interfacial zone ( $\times 2000)$

Figure 8. SEM images of dry and saturated specimen. 


\section{Discussion}

The composition and properties of concrete at each scale play a role in its strength and affects it at the upper scale due to the multiscale nature of concrete. In this section, the drying effects on compressive strength will be discussed form four scales-C-S-H, cement paste, mortar, and concrete.

In $\mathrm{C}-\mathrm{S}-\mathrm{H}$ scale, $\mathrm{C}-\mathrm{S}-\mathrm{H}$ gel is made up of the aggregation of $\mathrm{C}-\mathrm{S}-\mathrm{H}$ granules. The interaction between water and C-S-H gel determines the mechanical properties of cementitious materials [15]. Water removal from the interlayer space and intraglobular pores (IGP) causes the C-S-H globule collapse and results in the changes of $\mathrm{C}-\mathrm{S}-\mathrm{H}$ sheets in shape and orientation, relative to their nearest neighbors [28]. As shown in Figure 13 in Reference [30] by Zhang et al., the removal of interlayer water and gel water caused by heating leads to the $\mathrm{C}-\mathrm{S}-\mathrm{H}$ grain shrinkage, and further, to shrinkage of concrete at three scales. Furthermore, the impact of water on the performance of C-S-H gel was interpreted from the perspective of molecular dynamics. Water molecules can change the connections in C-S-H gel by screening the $\mathrm{Ca}-\mathrm{O}$ connections and replacing the ionic-covalent bond with unstable H-bond connections, which can be shown from Figures 8 and 11 in Reference [31]. The hydrolytic weakening of water molecules reduces the stiffness and cohesive force of $\mathrm{C}-\mathrm{S}-\mathrm{H}$ gel, as a result of the reduction in compressive strength. The molecular simulation of Hou et al. [31] had indicated that compressive strength of dry C-S-H was 33.3\% higher than that of saturated C-S-H. As the dominant cement hydrate, the reduction of compressive strength in $\mathrm{C}-\mathrm{S}-\mathrm{H}$ scale provides an explanation for the strength changes caused by drying in higher scales of concrete.

Cement paste scale is composed of hydration products $(\mathrm{C}-\mathrm{S}-\mathrm{H}, \mathrm{CH}, \mathrm{AFt}, \ldots)$, dehydrated clinkers, and capillary pores. According to the Kelvin-Laplace equation, water confined in capillary pores is under compression. When paste is exposed to drying conditions, capillary water is gradually lost and smaller and smaller pores are emptied. The water loss from large capillary pores has less contribution on shrinkage than that from small capillary pores, so in the early stage of the drying process more water loss just results in relatively small shrinkage. The drying shrinkage of paste is only about $1 / 4$ of the total shrinkage when about $70 \%$ of the water is lost, as shown in Figure $6 \mathrm{a}$. On the other hand, the dry and saturated paste behaves differently under compression loading. For the dry paste, which has a higher stiffness than saturated paste, more energy is required when microcracks are driven to extend through, and microcracks in other weak regions may propagate or new microcracks may initiate to reduce local stress intensity. This will result in a higher compressive strength a columnar failure mode, and the development of more microcracks (Figure $5 b$ ). For the saturated paste, however, the growth of microcracks is easier because water reduces the surface free energy of solid phase [5]. Thus, the saturated paste fails in a lower compressive strength and presents a failure mode with a main crack on surface (Figure 5a).

The mortar scale is composed of cement paste, sand, and interface transition zone (ITZ) between paste and sand, of which cement paste is the origin of strength and ITZ is the weakest phase [15]. Due to the introduction of sand, mortar has higher stiffness and lower water content than cement paste with the same water/cement ratio, and thus presents the smaller shrinkage with the loss of water. When subjected to compression loading, microcracks in mortar grow mainly along the ITZ as shown in Figure 9. They propagate and coalesce into macro-cracks. On one hand, drying makes paste stiffer and stronger, on the other hand, it causes the bonding between sand and paste to get weaker, as well as increasing the porosity within $100 \sim 1000 \mathrm{~nm}$. Therefore, the strength increase of mortar $(13.27 \% \sim 15.45 \%)$ caused by drying is not as pronounced as that of cement paste $(23.91 \% \sim 25.73 \%)$, as shown in Figure 4.

Concrete scale is composed of mortar, coarse aggregate, and ITZ between mortar and coarse aggregate. The introduction of coarse aggregate with higher stiffness not only results in the smaller deformation of concrete than mortar and cement paste in drying process (Figure 6c), but also results in the more complicated ITZ with a higher volume content. Similarly, when subjected to compression loading, failure of concrete results from the propagation, and coalescence of microcracks, which depends to a large extent on the performance of ITZ. For dry concrete, the harmful effect to strength 
due to the weakened bonding between coarse aggregate and mortar is greater than mortar. Therefore, the saturation effect on compressive strength of concrete is less pronounced $(4.23 \% \sim 5.26 \%)$ than that of mortar $(13.27 \% \sim 15.45 \%)$, as shown in Figure 4.

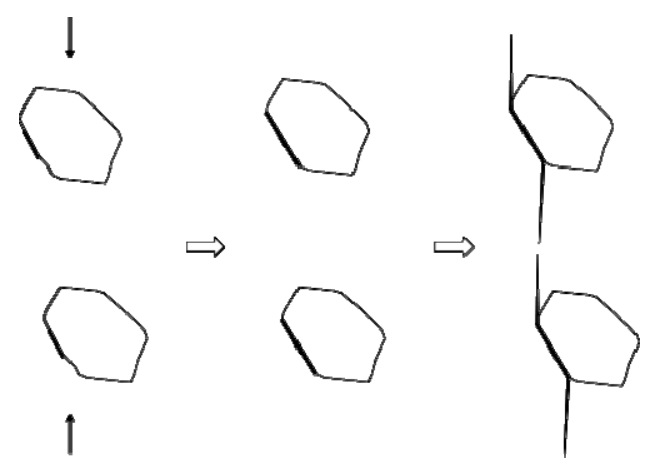

Figure 9. Microcrack growth under compression loading.

From above analysis, it can be seen that the drying effect on compressive strength is different at three scales. On one hand, the denser microstructure and further cement hydration caused by drying promote the strength increase. On the other hand, the porosity increase and the coarsened pore structure, as well as the weakened bonding between paste and aggregate, would cause strength reduction. The drying effect on compressive strength of concrete is the result of competition between the strengthening effect and the weakening effect. From cement paste to mortar and concrete, the drying-strengthening effect on strength decreases with the decrease of paste content. The authors analyzed some experimental results from other researchers and found that the difference in compressive strength between dry and saturated concrete at different scales was closely related to the paste content. Results from the literature $[4,9,12,24,31-33]$, as well as our test data, are plotted in Figure 10. It is evident that the drying effect on compressive strength decreases significantly with the decrease of paste content.

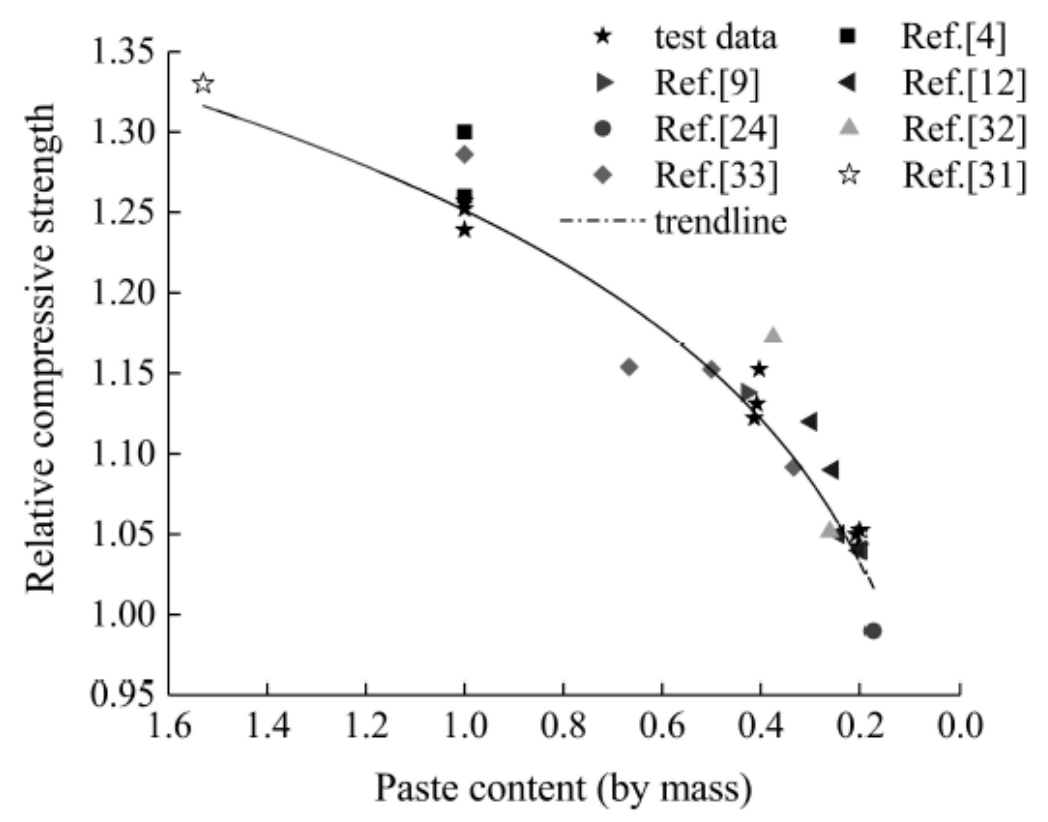

Figure 10. Relative compressive strength versus mass fraction of paste. (th represents the data from molecular simulation of C-S-H. C-S-H accounts for $60 \% \sim 70 \%$ of hydration products, here it takes the middle value of $65 \%$. So preparing a unit mass of $\mathrm{C}-\mathrm{S}-\mathrm{H}$ requires 1.54 unit mass of cement paste.) 


\section{Conclusions}

The isothermal drying process of cement paste, mortar, and concrete, as well as drying effect on the compressive strength were investigated in this paper, and the main conclusions are as follows:

(1) The isothermal drying process of concrete at three scales is very similar and can be divided into three stages: rising-rate drying, falling-rate drying, and slow drying stage. Water-losing rate, final water loss, and the time required to completely dry state are all related to the paste content.

(2) After isothermal drying, cement paste, mortar, and concrete all exhibit apparent shrinkage; The porosity and average pore diameter of cement paste and mortar increase. This porosity increase in cement paste is mainly attributed to pores less than $100 \mathrm{~nm}$, while in mortar it is attributed to the pores within 100 1000 nm.

(3) Drying has a strengthening effect on the compressive strength of cement paste, mortar, and concrete, which increases with the increase of paste content; the increase in compressive strength of concrete mainly comes from the increase in paste strength and water/cement ratio has little influence on this strengthening effect.

(4) The drying effect on compressive strength of concrete is the result of competition between the strengthening effect and the weakening effect. The former results from the densified microstructure and further hydration due to drying, and the latter results from the propagation of microcracks and the increase of porosity caused by drying.

Author Contributions: Conceptualization, X.D. and Z.L.; formal analysis, X.D.; funding acquisition, Z.L. and X.D.; methodology, X.D., T.T., and B.L.; supervision, T.T., B.L., and H.L.; visualization, X.D. and Z.L.; writing-original draft, X.D., Z.L, T.T., and B.L.; writing-review and editing, X.D., Z.L., and H.L.

Funding: This research was funded by National Natural Science Foundation of China, grant number 51379178, National Key R\&D Plan of China, grant number 2017YFC0405101-2.

Conflicts of Interest: The authors declare no conflicts of interest.

\section{References and Note}

1. Bartlett, F.M.; Macgregor, J.G. Effect of moisture condition on concrete core strengths. ACI Mater. J. 1994, 91, 227-236.

2. Glucklich, J.; Korin, U. Effect of Moisture Content on Strength and Strain Energy Release Rate of Cement Mortar. J. Am. Ceram. Soc. 1975, 58, 517-521. [CrossRef]

3. Wu, Z.; Wong, H.S.; Buenfeld, N.R. Transport properties of concrete after drying-wetting regimes to elucidate the effects of moisture content, hysteresis and microcracking. Cem. Concr. Res. 2017, 98, 136-154. [CrossRef]

4. Ross, C.A.; Jerome, D.M.; Tedesco, J.W. Moisture and strain rate effects on concrete strength. ACI Mater. J. 1996, 93, 293-300.

5. Wittmann, F.H. Interaction of hardened cement paste and water. J. Am. Ceram. Soc. 2010, 56, 409-415. [CrossRef]

6. Bažant, Z.P. Constitutive equation for concrete creep and shrinkage based on thermodynamics of multiphase systems. Matériaux Constr. 1970, 3, 3-36. [CrossRef]

7. Liu, B.D.; Lv, W.J.; Li, L.; Li, P.F. Effect of moisture content on static compressive elasticity modulus of concrete. Constr. Build. Mater. 2014, 69, 133-142. [CrossRef]

8. Korpa, A.; Trettin, R. The influence of different drying methods on cement paste microstructures as reflected by gas adsorption: Comparison between freeze-drying (F-drying), D-drying, P-drying and oven-drying methods. Cem. Concr. Res. 2006, 36, 634-649. [CrossRef]

9. Zhou, J.K.; Chen, X.D.; Wu, L.Q.; Kan, X.W. Influence of free water content on the compressive mechanical behavior of cement mortar under high strain rate. Sadhana 2011, 36, 357-369. [CrossRef]

10. Wang, H.L.; Li, Q.B. Experiments of the compressive properties of dry and saturated concrete under different loading rates. J. Hydraul. Eng. 2007, 26, 84-89.

11. Pihlajavaara, S.E. On the Main Features and Methods of Investigation of Drying and Related Phenomena in Concrete; State Institute for Technical Research: Helsinki, Finland, 1965. 
12. Han, J.S.; Li, Z.L.; Liu, H.J.; Zhang, G.H.; Tan, C.; Han, J.J. Study on the process of isothermal continuous dry and its effect on the strength of concrete of different strength grades. Constr. Build. Mater. 2018, 187, 14-24. [CrossRef]

13. Kanna, V.; Olson, R.A.; Jennings, H.M. Effect of shrinkage and moisture content on the physical characteristics of blended cement mortars. Cem. Concr. Res. 1998, 28, 1467-1477. [CrossRef]

14. Skoczylasa, F.; Burlionb, N.; Yurtdas, I. About drying effects and poro-mechanical behaviour of mortars. Cem. Concr. Compos. 2007, 29, 383-390. [CrossRef]

15. Mehta, P.K.; Monteiro, P. Concrete: Structure, Properties and Materials; Prentice-Hall, Inc.: Englewood Cliffs, NJ, USA, 2006.

16. Wittmann, F.H. Surface tension, shrinkage and strength of hardened cement paste. Matériaux Constr. 1968, 1, 547-552. [CrossRef]

17. Maruyama, I.; Sasano, H.; Nishioka, Y.; Igarashi, G. Strength and Young's modulus change in concrete due to long-term drying and heating up to 90 C. Cem. Concr. Res. 2014, 66, 48-63. [CrossRef]

18. Maruyama, I.; Nishioka, Y.; Igarashi, G. Microstructural and bulk property changes in hardened cement paste during the first drying process. Cem. Concr. Res. 2014, 58, 20-34. [CrossRef]

19. The National standards of the People's Republic of China. Test Code for Hydraulic Concrete SL 352-2006.

20. Taylor, H.F.W. Cement Chemistry, 2nd ed.; Thomas Telford Publishing: London, UK, 1997.

21. Hansen, T.C. Physical structure of hardened cement paste. A classical approach. Mater. Struct. 1986, 19, 423-436. [CrossRef]

22. Chen, D.Y.; Li, M.; Zhu, X.F. TG-DSC method applied to drying characteristics and heat requirement of cotton stalk during drying. Heat Mass Transf. 2012, 48, 2087-2094. [CrossRef]

23. Bazant, Z.P.; Najjar, L.J. Drying of concrete as a nonlinear diffusion problem. Cem. Concr. Res. 1971, 1, 461-473. [CrossRef]

24. Carlson, R.W. Drying shrinkage of large concrete members. ACI J. 1937, 33, 327-336.

25. Zhang, G.H.; Li, Z.L.; Zhang, L.F.; Shang, Y.J.; Wang, H. Experimental research on drying control condition with minimal effect on concrete strength. Constr. Build. Mater. 2016, 135, 194-202. [CrossRef]

26. Jennings, H.M. Refinements to colloid model of C-S-H in cement: CM-II. Cem. Concr. Res. 2008, 38, $275-289$. [CrossRef]

27. Wang, J.; Lacarrièren, L.; Sellierm, A. Multicomponent modelling of cement paste dehydration under different heating rates. Mater. Struct. 2019, 52, 136-145. [CrossRef]

28. Okpala, D.C. Pore structure of hardened cement paste and mortar. Int. J. Cem. Compos. Lightweight Concr. 1989, 11, 245-254. [CrossRef]

29. Stepkowska, E.T.; Blanes, J.M.; Franco, F.; Real, C.; Pérez-RodríGuez, J.L. Phase transformation on heating of an aged cement paste. Thermochim. Acta 2004, 420, 79-87. [CrossRef]

30. Zhang, Q.; Ye, G.; Koenders, E. Investigation of the structure of heated Portland cement paste by using various techniques. Constr. Build. Mater. 2013, 38, 1040-1050. [CrossRef]

31. Hou, D.S.; Ma, H.Y.; Zhu, Y.; Li, Z.J. Calcium silicate hydrate from dry to saturated state-Structure dynamics and mechanical properties. Acta Mater. 2014, 67, 81-94. [CrossRef]

32. Wang, H.L.; Jin, W.; Li, Q. Saturation effect on dynamic tensile and compressive strength of concrete. Adv. Struct. Eng. 2009, 12, 279-286. [CrossRef]

33. Li, Q.H.; Yao, Y.; Sun, B.; Li, Z.J. Mechanism of effect of elevated temperature on compressive strength of cement mortar. J. Build. Mater. 2008, 11, 699-703. (In Chinese)

(C) 2019 by the authors. Licensee MDPI, Basel, Switzerland. This article is an open access article distributed under the terms and conditions of the Creative Commons Attribution (CC BY) license (http://creativecommons.org/licenses/by/4.0/). 